\title{
LA VIDA EN RESTO. CUERPOS Y BASURA EN ALICIA DUJOVNE ORTIZ, FERNANDO BRITO Y MANUEL PINEDO ${ }^{1}$
}

\author{
Remains of life. Bodies and Trash in Alicia Dujovne Ortiz, Fernando Brito \\ and Manuel Pinedo
}

\author{
Nuria Girona Fibla* \\ * Universidad de Valencia/Universitat de València \\ nuria.girona@uv.es
}

\begin{abstract}
Palabras clave
Inmunidad

Biopolítica

Basura

Resumen

A partir de tres propuestas distintas: la crónica periodística ¿Quién mató a Diego Duarte? Crónicas de la basura de Alicia Dujovne Ortiz (2011), la serie fotográfica de Tus pasos se perdieron en el paisaje de Fernando Brito (2009) y la novela Plop (2007) de Rafael Pinedo, se aborda cómo, en medios diversos (periodismo, imagen y ficción) se redefine la distinción entre vida y muerte contra su demarcación inmunitaria. Las tres producciones comparten esta figuración del cuerpo en tanto desecho y residuo: la crónica de Dujovne lo inserta en el circuito económico de la producción y el consumo; las fotos de Brito parten igualmente de la condición de abandono de esos cuerpos y su aplanamiento en la basura, aunque el contexto visual en el que se integran es un paisaje falsamente natural; por último la novela Plop radicaliza la noción de resto en una ficción futurista donde ese circuito económico y ese medio natural ha quedado devastado.
\end{abstract}

Resto

\section{Keywords}

Immunity

Biopolitics

Waste

Remains

\section{Abstract}

From three different proposals: ¿Quién mató a Diego Duarte? Crónicas de la basura by Alicia Dujovne Ortiz (2011), the photographical series of Tus pasos se perdieron en el paisaje by Fernando Brito (2009) and the novel Plop (2007) by Rafael Pinedo, it's adressed how, in different media (periodism, image and fiction) the distinction between life and death is redefined against its immune demarcation. The three productions share this figuration of the body as waste and residue: Dujovne's chronicle inserts it into the economic cycle of production and consumption; Brito's photos also start from the condition of abandonment of these bodies and their flattening in the garbage, although the visual context in which they are integrated is a falsely natural landscape; finally the novel Plop radicalizes the notion of the remains in a futuristic fiction in where that economic cycle and that natural environment has been devastated.

Girona Fibla, N. (2018). La vida en resto. Cuerpos y basura en Alicia Dujovne Ortiz, Fernando Brito y Manuel Pinedo. Papeles del CEIC. International Journal on Collective Identity Research, vol. 2018/1, papel 190, CEIC (Centro de Estudios sobre la Identidad Colectiva), UPV/EHU Press, http://dx.doi.org/10.1387/pceic.17728

\footnotetext{
${ }^{1}$ Este artículo forma parte de la investigación realizada en el marco del Proyecto I+D del Ministerio de Economía y Competitividad titulado Cultura y nuevos movimientos sociales. Prácticas, discursos y representaciones (referencia FFI2014-55207-P).
} 
Pero el cadáver, ay, siguió muriendo. César Vallejo

\section{LA CAJA NEGRA DE LA BIOPOLÍTICA}

Una de las consideraciones más reiteradas de Michel Foucault para describir el nacimiento de la biopolítica es la referida al paso del poder de "hacer o dejar vivir" a un nuevo derecho "que no borraría el primero pero lo penetraría, lo atravesaría, lo modificaría y sería un derecho, o mejor, un poder exactamente inverso: poder de hacer vivir y dejar morir" (2000: 218). La organización del poder ya no se ejerce entonces tanto en la posibilidad de matar sino en la expectativa de invadir la vida entera. En ninguno de los dos casos vida y muerte se disponen como alternativas excluyentes.

La muerte resulta funcional para la exigencia de reproducción de la vida en el orden biopolítico. El cambio decisivo que impone ese orden se da cuando la muerte deja de ser externa al mecanismo de producción de la vida, cuando penetra en el recinto que parece excluirla. "Allí busca Foucault la caja negra de la biopolítica", afirma Roberto Esposito (2005: 193):

"En el espacio liminar en que la muerte no es solo una figura arcaica respecto de la cual se determina la vida y tampoco el precio trágico que esta debe pagar por su propia expansión, sino más bien un pliegue interno de la vida, una modalidad o —tonalidad-de su propia conservación" (2005: 193).

Pero según Esposito, esta noción de biopolítica contiene una tensión irresuelta entre vida y poder en cuanto que la relación entre ambas puede presentarse como la de "un poder de la vida" o la de "un poder sobre la vida". La categoría de inmunidad permitiría articular estas dos vertientes: la afirmativa, productiva, y la negativa, mortífera; en su doble sentido biológico y jurídico constituye el punto de tangencia entre la esfera de la vida y el derecho. Vida y poder, en lugar de quedar sometidos entre sí, resultan con la noción de "inmunidad" constituyentes de una unidad inescindible: no existe un poder exterior a la vida, así como esta nunca se produce fuera de su relación con el poder, en el nudo que ata la protección de la vida a su potencial negación: "esto significa que la negación no es la forma de sujeción violenta que el poder impone a la vida desde fuera, sino el modo esencialmente antinómico en que la vida se conserva a través del poder. 
Desde este punto de vista, bien puede aseverarse que la inmunización es una protección negativa de la vida (2006: 74). Solo así se entiende cómo una política de la vida puede convertirse en una tanatopolítica, es decir, una práctica de la muerte. La defensa inmunitaria, cuando va más allá de ciertos límites, determina la crisis del mismo organismo que desea defender, como sucede con las enfermedades autoinmunes ${ }^{2}$.

La política entra de lleno en el paradigma inmunitario cuando toma la vida como contenido directo de su actividad. Su objetivo ya no es una "forma de vida" cualquiera sino la vida misma: "toda la vida y solo la vida, en su simple realidad biológica" (Esposito, 2005: 160), ya sea la del individuo o la de la especie, que inmuniza de los riesgos que amenazan con extinguirla. Esposito destaca que el modo en que la política captura su objeto se concentra en el régimen del cuerpo, ya que ese "lugar privilegiado para el despliegue de la vida, también es donde más se advierte la amenaza de muerte" (ibídem: 161).

El cuerpo se presenta en consecuencia como un lugar de contención de la vida, cuyos límites constituyen líneas defensivas contra su aniquilación (la enfermedad, el envejecimiento, el deterioro, etc.). En esta dirección podemos preguntarnos por los límites que inmunizan la vida en los cuerpos y por su representación: ¿qué aísla un cuerpo de la muerte?, ¿qué zona, qué contorno lo cierra para preservar la vida?

En los apartados siguientes enfocaré justamente las figuraciones textuales y artísticas de esos límites en relación con la "carnadura" del cuerpo y la consistencia biológica que lo encierra. De entre todas ellas, la del muerto viviente reúne en un organismo la intrusión de su fin por excelencia, como si el mayor peligro de la vida misma a la que antes hacía referencia fuera la muerte misma, además de representar en su

\footnotetext{
${ }^{2}$ Tal y como el nazismo invirtiera la proporción entre vida y muerte a favor de la segunda, hasta el punto de proyectar su propia autodestrucción. La particularidad de la enfermedad contra la que se pretendió defender al pueblo alemán se presentaba como una patología infecciosa: lo que se quería evitar a toda costa era el contagio de seres superiores por seres inferiores: "pero justamente el único modo de sellar el imposible contagio pareció ser el de eliminar a todos los posibles portadores, y no solo a ellos, sino también a todos los alemanes que podían haber sido contagiados, así como aquellos que podrían serlo en un futuro. Con la guerra perdida y con los rusos a pocos kilómetros, los posibles portadores eran ya todos. Aquí el paradigma inmunitario de la biopolítica nazi alcanza la cima de su furia autogenocida. Tal como sucede en la enfermedad autoinmune más devastadora, el potencial defensivo crece hasta el punto de volverse contra sí mismo" (Esposito, 2009: 152).
} 
tránsito la práctica política del hacer vivir y dejar morir ${ }^{3}$. El zombie es sin duda su correlato más evidente, en la imprecisión de su estado, figura del contagio pero, a la vez, figura que encarna un contagio en su propio ser y pulsa la imposible inmunización de la muerte. Podemos discutir qué retorna con el zombie, pero lo cierto es que, como cadáver viviente, remite a un resto, a un cuerpo cuya materialidad orgánica, más o menos descompuesta, resiste en su disolución.

Si por un lado el cadáver viviente realza que donde hay muerte existe un cuerpo (a menudo negado o desaparecido en las prácticas tanatopolíticas), por otro invoca la persistencia de la vida de la que ha sido separado. Aunque no me centraré en esta figura, me interesan las formas que puede cobrar su materialidad corporal como resto o sobrante: basura, desperdicio, despojo, ruina, etc., dado que las dualidades que reviste el paradigma inmunitario adoptan la semántica de la infección, de la contaminación, de la pureza, de la integridad, etc. En esta segregación entre vida y vida humana, cuerpo y persona, el estatuto de lo orgánico se vuelve político.

A partir de tres propuestas distintas: la crónica periodística en ¿Quién mató a Diego Duarte? Crónicas de la basura de Alicia Dujovne Ortiz (2011), la serie fotográfica de Tus pasos se perdieron en el paisaje de Fernando Brito (2009) y la novela Plop (2007) de Rafael Pinedo, abordaré cómo, en tres medios diversos (periodismo, imagen y ficción), se redefine la distinción entre vida y muerte contra su demarcación inmunitaria. Las tres producciones comparten esta figuración del cuerpo en tanto desecho y residuo. La crónica de Dujovne lo inserta en el circuito económico de la producción y el consumo; las fotos de Brito parten igualmente de la condición de abandono de esos cuerpos y su aplanamiento en la basura, aunque el contexto visual en el que se integran es un paisaje falsamente natural. Por último la novela Plop radicaliza la noción de resto en una ficción futurista donde ese circuito económico y ese medio natural ha quedado devastado.

\footnotetext{
${ }^{3}$ La condición de muerto viviente se extiende como forma de existencia social que alcanza a poblaciones enteras, según expone Achille Mbembe en relación con la tanatopolítica contemporánea, que denomina "necropolítica". La propagación difusa del derecho a matar más allá del Estado perfila "mundos de muerte" no solo territoriales sino también subjetivos, ya que "el poder de la muerte nubla las fronteras entre resistencia y suicidio, sacrificio y redención, mártir y libertad" (2011: 75).
} 
Las tres producciones giran en torno a la noción de supervivencia, a la par que suspenden con mayor o menor éxito la centralidad de cierta configuración de lo humano y de lo antropocéntrico. Sus personajes (más bien umbrales vivientes) habitan zonas de abandono o de contagio donde los cuerpos caen pero quedan como vida. Esos espacios se alistan en lo que Gabriel Giorgi denomina "paisajes de sobrevida", donde opera un doble desmontaje:

"El de la oposición entre vivo/muerto, volviéndolo instancia de una cierta tensión, de una resonancia o una vibración, y por otro el de la centralidad normativa de lo humano, justamente porque lo que aparece como instancia de sobrevida y de supervivencia son materias y tiempos no humanos" (2016: 133) ${ }^{4}$.

En estos paisajes, lo que la biopolítica coloca del lado de la muerte no se resta a la vida.

\section{UN CADÁVER ENTERRADO EN LA BASURA}

"Los basureros son los héroes olvidados de la modernidad", afirma Zygmunt Bauman: "un día sí y otro también, vuelven a refrescar y a recalcar la frontera entre normalidad y patología, salud y enfermedad, lo deseable y lo repulsivo, lo aceptado y lo rechazado, lo comme il faut y lo comme il ne faut pas, el adentro y el afuera del universo humano" (2005: 43). Pero esta frontera entre productos útiles y residuos es cualquier cosa menos "natural". Por el contrario, es ella "la que predice, literalmente al parecer, la diferencia entre ellos: la diferencia entre lo admitido y lo rechazado, lo incluido y lo excluido" (ibidem: 43).

Bauman señala que el diligente afán por eliminar o invisibilizar esos residuos responde a un imperativo de orden y de separación que se extiende al tratamiento de las vidas consideradas "superfluas" en el progreso económico. La invasión de desechos amenaza los espacios y la

\footnotetext{
${ }^{4}$ También en Formas comunes. Animalidad, cultura y biopolítica Giorgi observa, a partir de Agamben, que ciertas ficciones contemporáneas en América Latina plantean una disociación entre la "persona" y la "cosa viviente" como problema a la vez estético y político: "La dislocación de la 'vida desnuda' aparece, en este sentido, como material común a escrituras que hacen de ese límite ambivalente con la vida biológica una dimensión de exploración y de experimentación, trabajando el espaciamiento o separación entre el 'sujeto' (el individuo, la persona, el yo, etc.) y ese resto corporal, biológico, ese 'ser viviente' sin cualificaciones en el que, por factores que involucran dimensiones políticas, se convierten" (Giorgi, 2014: 42).
} 
vida de las sociedades contemporáneas al ritmo que su población "excedente" (inmigrantes, refugiados y demás parias) se desborda y se hace más difícil su contención. El paradigma inmunitario se reviste aquí tanto de higiene y salubridad como de productividad y utilidad económica. Lo que queda como resto (sucio, inútil, contaminante) se allana en la basura, esa frontera de objetos, materiales, cuerpos y vidas residuales, abandonados a su suerte, olvidados del Estado y del capital ${ }^{5}$.

¿Quién mató a Diego Duarte? Crónicas de la basura de Alicia Dujovne Ortiz $(2011)^{6}$ se ubica en esta frontera de la economía residual a partir del caso de un adolescente que murió enterrado en uno de los basurales de Buenos Aires. Los hechos acontecieron en 2004, cuando buscaba metales en una montaña de residuos para poder revenderlos y comprar unas zapatillas deportivas para su hermano. A la llegada de la policía y los vigilantes del sumidero se ocultó bajo un cartón; minutos después, la descarga de un camión de desechos terminaba con su vida. Su cuerpo nunca se encontró y el caso fue archivado.

El formato de la crónica periodística le sirve a Dujovne Ortiz para relatar en primera persona lo que desde las páginas iniciales se presenta como una inmersión en los vertederos de la capital argentina. Si por un lado, la apostilla inicial ("Los hechos relatados en esta crónica son verídicos", 4) asegura su anclaje referencial, la estructura en capítulos y la disposición de una trama denotan la ficcionalización del acontecimiento. La versatilidad del género permite incluir distintos materiales procedentes de las conversaciones con los implicados en el caso, de las actas del juicio, de ensayos y trabajos académicos, etc., sin ocultar la mediación autoral ni esconder sus valoraciones. Porque lo que se presenta en las primeras páginas como un encargo (una exposición de arte cartonero en

\footnotetext{
${ }^{5}$ Las vidas desperdiciadas de Bauman evocan los "muertos vivientes" de Mbembe y, al decir de sus propias palabras, sugieren la "nuda vida" de Agamben: "el homo sacer es la principal categoría del residuo humano en el curso de la producción moderna de reinos soberanos ordenados" (Bauman, 2005: 49). Igualmente, en sus apuntes para una sociología de la basura, Gabriel Gatti rastrea hasta dónde la materialidad de las representaciones que ordenan la realidad social se encuentra en los estercoleros de la modernidad, en la basura ("esa materia disociada de sus sentidos"). Cuando los desperdicios estallan, cuando los contenedores de los recortes sobrantes de la lógica moderna rebosan, "la basura adopta un estatuto tan sugerente como paradójico: sigue siendo basura -está fuera-, pero es parte del mundo que la expulsa -está dentro-. Creo - estoy lejos de ser el único- que buena parte de la vida social contemporánea comparte con la basura ese estatuto tan singular (estar fuera pero dentro)" (Gatti, 2009: 3).

${ }^{6}$ Todas las citas de la obra corresponden a la edición citada en la bibliografía final. En adelante los números entre paréntesis indican la página.
} 
la embajada argentina de París) se convierte en una investigación sobre las circunstancias de la muerte de Diego Duarte y una exploración del medio donde tuvo lugar. De hecho, en la medida en que avanza el relato y se va desgranando el enigma, se introducen las reflexiones de lo que se presenta como "Elementos de basurología" (título de uno de sus capítulos), en un trazado geográfico de los suburbios argentinos y un tratado sociológico de sus habitantes y su relación con los desechos, que detallaré a continuación.

"Todo el Conurbano es un único charco que nadie piensa en sanear" (52), afirma uno de los personajes. El enclave donde transcurren los hechos forma parte del llamado "corredor sanitario" que en 1978 emplazó en la periferia el enterramiento de los residuos sólidos procedentes de la ciudad. La instalación de estos grandes "complejos ambientales" surgió como alternativa ante el crecimiento incontrolado de basurales a cielo abierto y la contaminación del aire producida por la incineración: "la idea originaria de los militares era 'limpiar' la capital y llevar la basura allí donde, en terrenos anegadizos, solo podian vivir los pobres. La explicación era que la ciudad no tenía terrenos suficientes para enterrar su basura" (Federovisky en Cores, 2012). La propuesta contemplaba no solo el alejamiento sino la invisibilización de los residuos. El método del enterramiento de basura, conocido en la jerga técnica como "relleno sanitario", pretendía hacerla desaparecer bajo tierra, como si el ciclo natural de la descomposición pudiera detenerse al ocultarlo a la vista. El proyecto no solo ignoraba el impacto medioambiental de los residuos, sino que supuso el comienzo de una batalla por la propiedad y la gestión de los residuos, además de sellar el margen de la urbe como espacio de desechos y pobreza. El cordón inmunitario que inicialmente podía asegurar las condiciones sanitarias de la población se erige entonces como un ordenamiento biopolítico que distribuye el valor de la vida -en este caso a partir de la equiparación, como sugería Bauman-, de residuos con residuos humanos y de la separación entre vidas que desechan y vidas desechables. Porque en torno a los vertidos de esta zona, como en otras, surgieron diversos asentamientos humanos que fueron creciendo en la medida en que la recuperación de residuos en la quema se convirtió en un modo de vida, mucho más con la implementación de las políticas neoliberales en el país y la crisis del año 2001. 
De todo ello da cuenta la obra para perfilar una noción de basura como resto procedente de la producción y el consumo en la lógica del capital, en cuya materialidad se confunde la vida humana con lo excremencial, tal y como evidenció el caso de Diego Duarte.

"Todo Suárez está hecho sobre un basural" (12), comenta otro de los protagonistas al referirse al vertedero de José León Suárez, en el partido General San Martín, donde murió Diego Duarte, el mismo lugar donde en 1956 fueron fusilados clandestinamente un grupo de rebeldes peronistas contra la dictadura gobernante y que Rodolfo Walsh relataría en Operación masacre (1957), hecho que la periodista no deja de recordar.

La crónica recupera los precedentes de este enclave en su propósito de historizar la basura para mostrar que la producción de residuos se articula en un circuito que es a la vez económico, social, político y cultural. No hay un objeto o sustancia de la basura, sino un proceso de basurización que enlaza objetos y sujetos investidos como excrementos. Desde la lógica del capital, la basura es un resto material que cosifica relaciones de producción y de consumo y esa lógica es la que lleva a la basurización de esos flujos de materiales y personas. El capítulo que relata el encuentro con el abogado Raúl Álvarez resulta clarificador en ese aspecto: "Hay que tener en cuenta que basura siempre es acumulación de capital" (59), comenta el personaje en diálogo con la periodista. Su intervención da pie a la cita de sus trabajos sobre la fetichización de la basura (75-76). Desde su perspectiva, este término connota una uniformidad que se contradice con la diversidad sustancial y material que engloba. Si la mezcla indiscriminada la caracteriza, lo único que la define es su carácter de desecho. Pero esa decisión que descarta el valor de uso de un objeto se basa en el lugar que ocupa su dueño en la estructura social, en tanto lo que puede resultar inservible para uno puede ser aprovechable para otro, tal como la necesidad puede alargar la vida útil de un producto o determinar su reutilización.

Visto así, la basura encarna un ámbito de contagio absoluto (de materias, objetos, cuerpos y relaciones) que el desbrozado periodístico procede a aislar, paso previo necesario para devolver la vida a lo que quedó excluido de ella. De ahí la minuciosa labor de deslinde de la escritura en torno a la naturaleza misma de la basura (en la distinción entre los diferentes tipos de desechos: orgánicos, fluidos, domiciliarios, industriales, etc.), los modos de recuperación (reciclaje, reventa), la 
particularidad de cada uno de los actores sociales que la circundan (cirujas, cartoneros, quemeros, trabajadores en plantas, etc.) y de las distintas instancias que la velan (estatales y privadas). Al levantar esa "cáscara cósica" (76) de la basura (esa materialidad disolvente que oscurece todos los sobrantes), el excedente económico se alza como abundancia. Alli donde la vida perdió su forma emergen otras formas de vida que van del reciclaje al cooperativismo: "estamos creando un orden nuevo, hecho de construcciones subterráneas asociativas" (116), recoge la crónica en voz de uno los líderes del basural.

Alli donde el cuerpo de Diego Duarte desapareció como cadáver se cifra también el poder de hacer vivir y dejar morir; en este caso, de hacer vivir y dejar morir en la basura. Que su cuerpo jamás se encontrara eximió de la responsabilidad de su muerte: "Si el cuerpo no aparece no hay homicidio" (52, 127). La biopolítica $-y$ su reverso sistemático y complementario, la tanatopolítica- decide a la vez qué vidas valen y qué vidas no, qué cadáveres son rescatables y cuáles prescindibles, como ya vimos. En contrapunto, la crónica reconstruye su biografía. No se trata simplemente de escribir su vida y así individualizarla o humanizarla, sino de rescatarla como vida, donde lo humano incluye el reconocimiento de su existencia y de su muerte. "Después de todo, si alguien desaparece y esa persona no es nadie, ¿entonces qué y dónde desaparece y cómo puede tener lugar el duelo?", se pregunta Judith Butler en lo que describe como una distribución diferencial del dolor que "produce y mantiene ciertas concepciones excluyentes de quién es normativamente humano" (2006: 16-17). Una vida concreta no puede aprehenderse como dañada o perdida si antes no es aprehendida como viva. Esa es la función que cubre la parte biográfica de Diego Duarte en la crónica: contar la muerte que hace a la vida humana. Pero en la resolución del crimen y en el reparto de culpas colectivas que el capítulo final del libro esgrime ("No preguntes quién mató a Diego Duarte. Fuimos nosotros", 134) se erige el límite de quien narraba, en la inversión valorativa que propone del desecho: "mi recorrida por José León Suárez me ha permitido frecuentar a una humanidad merecedora de toda admiración", 134, en cómo el resto termina por sustentar su mejor yo:

En mi criterio lo más interesante y estimulante de la Argentina de hoy son estas "construcciones subterráneas" que levantan el nuevo orden sobre los restos del viejo. También en esto he resuelto creer. Ya no se trata de una fe basada en un testimonio, en unos ojos, en un gesto que no 
puede engañar. Es una fe originaria en la observación de un grupo de personas creativas que inventan la manera de no morir (134).

La autoridad de la enunciación cronística, como el ciruja, sabe distinguir, al abrir la bolsa, lo que resulta aprovechable y lo que no; como el cartonero, sabe devolver la vida al residuo; como el reciclaje, organiza los materiales heterogéneos... si no fuera porque la superioridad de esta instancia ordenadora no equivale a la invención obligada por la supervivencia. Paradojas del texto: ahí donde lo dicho propone una vida que no quede capturada en su resto, en su decir eleva la humanidad más humanizada de quien escribe.

\section{UN CADÁVER ABANDONADO EN EL PAISAJE}

El estatus del cuerpo como resto cobra otra dimensión en las fotografías del mexicano Fernando Brito. Aunque su materialidad se inscribe también en una economía residual, es el medio natural el que sirve, en contrapunto, para restaurar su humanidad.

En su colección Tus pasos se perdieron en el paisaje ${ }^{7}$ se observan cadáveres yacentes en medio de la naturaleza. Las fotografías fueron tomadas por el autor en paralelo a su trabajo como fotoperiodista de crónica roja en Sinaloa, una de las zonas más castigadas por el narcotráfico. Sobre su proceso de creación, Brito apunta:

“El proyecto arrancó en 2006 y hasta 2009 entró a una galería de Culiacán. Yo trabajé con el tema de la muerte generalizada, no importaba si se trataba de muertos por accidentes. Más adelante lo cercené a la cuestión de la denuncia directa hacia los asesinatos con violencia, y la única manera que veía para sacar a la luz esa denuncia era disfrazarlo de arte" (Valverde, 2013).

La reiteración de ciertos motivos y principios constructivos en estas fotografías contribuye a un efecto de serialidad de las escenas que enmarcan. En todas se muestra un paisaje natural en distintas versiones, bien mediante una vegetación frondosa, agreste, en ocasiones idilica,

\footnotetext{
${ }^{7}$ La colección a la que me refiero obtuvo, entre otros premios, el tercer lugar en la categoría Noticias Generales del World Press Photo 2011; el primer lugar en la 12. ${ }^{\text {a Bienal }}$ de Artes Visuales del Noreste 2009; el premio adquisición en la XIV Bienal de Fotografía 2010 del Centro de la Imagen; el premio Descubrimientos PhotoEspaña 2011, y la mención honorífica en la I Bienal Nacional del Paisaje en 2014. En https://www.youtube.com/watch?v=e0eCIBTyuCs se puede visualizar el vídeo del autor con el montaje de las fotografías.
} 
bien mediante una llanura extensa o tierra de nadie que se pierde en el horizonte. En el tratamiento fotográfico prima la horizontalidad o la profundidad que llena la vista y que se extiende fuera de marco. La hierba o los matojos apenas quedan contenidos en el encuadre, contribuyendo a un efecto expansivo del vacío que se retrata.

Esta naturaleza se muestra invariablemente sin huella de intervención humana ${ }^{8}$, pero allí donde lo vivo se desborda se descubre un bulto que interrumpe la continuidad de la vista y la armonía de la escena. La materialidad de un cuerpo muerto (una silueta humana más o menos entrevista) quiebra la panorámica, marca un hiato espacial, irrumpe en la quietud del paisaje. La mayoría de las veces, el foco no está puesto en ese cuerpo abandonado o evacuado en la maleza, como si un imprevisto o un acto fallido hubiera asaltado el instante fotográfico, pero nada más lejos del azar en la composición de esta naturaleza afectada que un cadáver casual. El cuerpo que no debía estar ahí funciona por contraste entre figura y fondo, lo vivo y lo muerto, lo natural y lo humano, lo humano y lo inhumano, lo que vemos y lo que queda oculto.

La naturaleza que acoge a este cadáver lo expone como resto, pero resto humano al fin y al cabo, en tanto se destaca como única presencia antropomórfica. Este desecho adquiere una diferencia humana en su límite todavía orgánico. El lugar equivocado que ocupa en el paisaje construye esta diferencia: muerto en medio de lo vivo, humano en medio de lo natural, humano frente a vegetal. A la vista queda que no puede solaparse con la basura que en otras ocasiones lo rodea. Presentifica, como el cuerpo perdido de Diego Duarte, el alcance de los contenedores biopolíticos.

Cuerpo muerto pero vida humana todavía, esa silueta reconocible tampoco se confunde con la tierra que lo alberga, no ha entrado aún en el ciclo biológico de la descomposición. Si en la convención del género pictórico de la naturaleza muerta, el cadáver animal o la fruta putrefacta encarnan lo inanimado, aquí el residuo persiste en el límite de lo humano. En todo caso, en la muerte de este cuerpo se visibiliza la condición de lo humano, precisamente lo que se intentó aniquilar en el

\footnotetext{
${ }^{8}$ Excepto por la presencia de caminos en algunas de las fotografías, que parecen designar un posible itinerario de tránsito por el interior del paisaje pero que, según apunta el título de la serie, también llevan a la pérdida de la vida.
} 
acto de matarlo, en esa secuencia que suponemos anterior a la fotografía.

Hasta aquí las antinomias por las que se rehabilita la humanidad a estos cuerpos arrojados impunemente, anónimos, olvidados, de la maquinaria del narco (Reguillo, 2012). Pero a diferencia de Dujovne Ortiz, el régimen de la representación en las fotografías de Brito deja al descubierto los límites de su visibilidad, ${ }^{9}$ en lo que se nos oculta y en lo imposible de ver.

El rostro de estos muertos ha quedado cubierto por la vegetación o mirando al suelo o vedado a la vista en la toma fotográfica. Igualmente el cuerpo queda escondido o cubierto por bolsas de plástico o telas. Las huellas de lo humano -quizá habría que decir de lo inhumanoasoman en la ejecución de la que han sido objeto: en las heridas que se dejan entrever, en las manos y los pies atados, en la posición forzada en la que han quedado, en la elección del lugar en el que han sido abandonados. Han padecido una muerte desnaturalizada que solo puede venir de una mano humana, una intervención nuevamente recalcada en la naturaleza silvestre que los aloja pero que, a diferencia de ella, no es inocente. Los cuerpos quedan como restos de una escena anterior a la que ya no tenemos acceso pero cuya violencia queda evocada, en un campo de acción ciego que de otra forma no nos sería visible (Lane, 2012).

Este fuera de campo inscribe definitivamente a estos cadáveres fuera de lugar. Alli donde fueron dejados caer, perdidos en un páramo, al borde de un camino, extraviados, se enmarca un afuera: un espacio natural intercambiable en la serie fotográfica, una tierra de nadie que ya no puede identificarse ni con las afueras de la ciudad (sin rastro de urbe ni de población). Su muerte se retrata así en el afuera de lo humano.

Por último, no pueden pasar desapercibidas las declaraciones que recogía al comienzo sobre los propósitos del autor: "la única manera que veía para sacar a la luz esa denuncia era disfrazarlo de arte". La

\footnotetext{
9 "Lo humano se afirma indirectamente en esa disyuntiva que vuelve la representación imposible - una disyuntiva expresada por la imposibilidad de la representación-. Para que la representación exprese entonces lo humano no solo debe fracasar, sino que debe mostrar su fracaso. Hay algo irrepresentable que sin embargo tratamos de representar, y esta paradoja queda retenida en la representación. En este sentido, lo humano no se identifica con la representación, pero tampoco se identifica con lo irrepresentable. Se trata más bien de aquello que limita el éxito de cualquier práctica representativa" (Butler, 2006: 180). Sigo así la propuesta de Butler de pensar los marcos de visibilidad en las imágenes como esquemas normativos de inteligibilidad entre lo que es humano y no lo es.
} 
estetización de su mirada queda tan enfatizada en las fotografías que podemos tomarla como un recurso más en las antinomias que antes planteaba: si el cuerpo muerto recupera su dimensión humana en medio del paisaje natural, también un ojo humano la registra y exhibe el artificio de la naturaleza representada.

Frente a las fotografías tomadas en su trabajo como especialista de la nota roja, que muestran el cadáver diseccionado, focalizan lo escabroso, tienden a desvincular la carne herida de la historia singular y cuya muerte no apela al espectador (Monroy, 2015), en estas Brito "muestra un paisaje que en principio incluye al observador a partir de la contemplación" y "toma una distancia considerable para enmarcar sus fotografías en un espacio que dota de contexto" (Monroy, 2015) ${ }^{10}$.

Lo que Brito toma como marco de sentido es el paisaje y en esta convención comienza el disfraz de su mirada ${ }^{11}$. Para que exista paisaje no basta que exista naturaleza, es necesario un punto de vista. El encuadre y la iluminación consignan su intervención en esta falsa naturaleza. La composición resulta artificiosamente impecable, casi limpia, en contraposición con lo representado.

Las instantáneas documentan tanto el hallazgo de los cadáveres como las marcas de estilo lo mediatizan: no engañan acerca de su naturaleza fotográfica. Huellas de quien observó y realzó lo que miraba, huellas de aquello que sucedió, huellas que nos confrontan con sus restos: vidas que faltan, falta hecha vida.

El crimen irrumpe en este estado natural, violenta la naturaleza, vuelve como un resto no simbolizado que ni la vista ni el paisaje pueden integrar. Los cuerpos de Brito sugieren un secreto mal guardado: no se

\footnotetext{
${ }^{10}$ También Rossana Reguillo, al considerar el narcotráfico como maquinaria, señala "la capacidad de resistir dos tentaciones cuando se trata de la violencia de la máquina: una estetización del horror que termina por borrar sus anclajes estructurales $y$, de otro lado, la evitación de una pornografía en la exhibición de cuerpos rotos" (2012).

${ }^{11}$ En algunas de ellas, esta mirada se cruza con la propia del dispositivo policial. Me refiero a aquellas en las que aparece una banda amarilla (que se supone que delimita la escena del crimen) o papeles torpemente dispuestos (que indican los números de las pruebas encontradas) y recuerdan fotos de archivo policiales. Sin embargo, "la cinta y las etiquetas no logran contener el peligro de los crimenes que buscan circunscribir, ni logran ofrecer santuario o consuelo para los muertos que aguardan. Las fotografías de Brito nos permiten imaginarnos un cauce constante de imágenes similares: 47.515 de ellas; todo el paisaje mexicano intervenido por cinta policial, todo el paisaje de México una escena de muertos sin enterrar" (Lane, 2012).
} 
puede esconder un cadáver naturalmente ni a fuerza de naturalizar la violencia en la que fue exterminado.

\section{4. $\quad . . ¿$ ¿ SI MAÑANA LA BASURA FUERA EL PAISAJE?}

En Plop, de Rafael Pinedo ${ }^{12}$, asistimos a la ficcionalización definitiva de un mundo de restos donde la vida apenas se modula en variaciones mínimas alrededor de la muerte. No en vano ha sido considerada por la crítica como una novela distópica, situada en un escenario postapocalíptico del que no se conoce "ni la ubicación temporal concreta ni el cataclismo que le dio origen" (Steimberg, 2012: 128), que tomaré como un "después" de explosión autoinmunitaria. La narración acontece en un tiempo y en un espacio remoto, caracterizado por la devastación, donde el paisaje es "siempre el mismo: "barro, hierros retorcidos, cascotes, basura, algún arbusto" (39), llueve todo el tiempo, el agua se contamina apenas toca el suelo, no hay comida y los depredadores acechan (ratas o perros salvajes pero también los humanos entre sí). Es precisamente ahí, en el umbral de pasaje entre lo orgánico y lo inorgánico, donde la obra se pregunta qué significa sobrevivir y se interroga por la cualidad humana de ese "sobre" cuando la vida se reduce a subsistencia.

En este universo arrasado, la lógica del resto adquiere otro estatus puesto que ya no constituye un margen sino un medio extremo de vida, en un mundo que no se rige por la productividad económica, como en la crónica de Diego Duarte, ni cuenta con una naturaleza viva, como en las fotos de Fernando Brito. La basura no constituye aquí lo potencialmente desechable (nada se desecha en este mundo terminal), sino el residuo de un mundo anterior, tanto lo que se descartó pero ha persistido como lo que esa hecatombe incierta ha convertido en ruinas. El desecho asegura estrictamente la vida, en lo que permite mantenerla no como una forma de pobreza sino como la única forma de cubrir necesidades básicas (comer, beber, resistir a los ataques de los animales y de otros grupos, etc.). El resto se erige en ley implacable puesto que en este medio solo subsisten las especies más aptas, lo que resta de vida a partir de sus desperdicios.

\footnotetext{
${ }^{12}$ Premio Casa de las Américas 2002. Todas las referencias entre paréntesis corresponden a la edición citada en la bibliografía final.
} 
En ese sentido, la novela relata tanto un final -el de un mundo que ha quedado extinguido (y cabe leer como premonitorio)-, como el comienzo de uno nuevo donde la precariedad redefine la forma y la materialidad de lo viviente. Pero para entender hasta dónde lleva la lógica del resto esta ficción es imprescindible referirse en primer lugar a su cronotopo. La indeterminación temporal de la novela remite a una "mezcla de épocas" cuyo universo "es un mundo de restos: restos de construcciones, de objetos, de costumbres" (Steimberg, 2012: 128), un tiempo sin memoria de su anterioridad a pesar de las ruinas que lo habitan. Si, por un lado, a partir de esas ruinas se deduce un tiempo pasado en el relato, podemos reconocer en ellas los rastros de nuestro presente, pero, a la vez, las formas de vida arcaicas que se describen (el nomadismo, la organización tribal, el trueque, etc.) evocan una era prehistórica, erigiendo así un futuro que es una vuelta atrás, un tiempo en el que los precedentes civilizatorios se confunden con los residuos de su avance técnico, con sus escombros y con exiguas formas de vida natural:

Entre las montañas de basura hay ratas. Insectos. Lo que más se encuentra son cucarachas. (...)

Entre pilas de basura se encuentra todo. La mayor parte es hierro y cemento. Pero hay mucha madera también. Y plásticos. De todas las formas. Y tela, casi siempre medio podrida.

Y aparatos. Que nadie sabe para qué son, o fueron.

El óxido cubre todo el metal. El hongo, la madera (20).

En esta confluencia de tiempos no se sabe lo que retorna ni lo que es nuevo. Las formas de organización social han quedado reducidas a grupos humanos dispersos donde las relaciones de parentesco y de poder se supeditan a la caza y la protección. Cada grupo posee sus ritos, fiestas y tabúes (22) que funcionan como esquemas mínimos de contención y regulación colectiva, sin importar demasiado sus contenidos. Podemos reconocer en estas formas trazos de nuestro conocimiento antropológico y etnográfico que también ha sido reducido a restos para armar la ficción y cuyo saber desconocen los personajes $^{13}$. La cultura, como la lectura en el clan de Plop, es un vestigio

${ }^{13}$ Reati retoma el término antropología especulativa propuesto por Juan José Saer para caracterizar la novela como una ficción que interroga sobre el otro y a la vez refleja nuestra propia naturaleza (Reati, 2013: 36). 
lejano, un esqueleto vacío de atributos que ha quedado fosilizado; como el lenguaje, ha perdido su cualidad simbólica, rebajado prácticamente a arquetipos: el grupo de Plop se denomina "el Grupo"; la llanura en la que habita, "la Llanura”; el lugar de reunión, "Ia Plaza”.

Pero, siguiendo con la temporalidad de la novela, no parece casual que se construya retrospectivamente. Las primeras páginas se ubican en el momento en el que el Plop está a punto de morir enterrado en un pozo. A cada palada de tierra que recibe le sobreviene una imagen de su vida. El final recupera de nuevo ese momento, en una estructura circular que conduce el relato a donde empezó y que apunta a un tiempo cíclico en el que la materia se reintegra en la materia. La frase con la que termina ("hace plop", 151) repite el sonido del cuerpo caído al nacer, que da nombre al protagonista. Se trata de una vuelta al origen, a ese barro elemental de donde vino: "Porque nunca había habido otra cosa que barro. Siempre había llovido. Siempre había hecho frío. (...) Nunca existió otra cosa que barro. Solo figuras cubiertas de barro, como él" (151). Es la materia como tal, la materia que "cae" tanto para vivir como para morir.

Este retorno al barro no propone un recordatorio trascendental de la insignificancia de la existencia sino de la vida humana en continuidad con la vida natural: de ella proviene y a ella regresa ${ }^{14}$. En el barro se vive y se muere, se pierde y se gana la vida, una vida despojada de silueta humana que siempre estuvo ahí, anterior a escisiones distintivas, en su pura diferencia. En esa franja imprecisa entre zoé y bios se dirime el relato, es decir, en la dislocación entre pura existencia biológica y vida cualificada, en tanto el principio de la vida no discrimina vida orgánica, primaria y elemental, de la que permite mantener los mínimos humanos. De tal modo, desde este ángulo toda forma se revela inmanente a la vida, toda vida se da solo a través de sus formas, toda zoé es un bíos y todo bíos es una zoé de la cual es inescindible. A esa conjunción de bíos y zoé, fuerza y forma, Esposito la denominaría

\footnotetext{
14 “En la temporalidad cíclica del cosmos y el barro, Plop remite a una inmanencia pura de vida, a un campo preindividual que no dibuja distinciones ni jerarquías en la intensidad múltiple, contingente y mutante de lo viviente" (Sánchez Idiart, 2016: 83). También Reati considera que esta circularidad "refuerza esa alegoría de la condición humana como un vivir sepultado en el barro atemporal: el transcurrir histórico es apenas un destello entre el origen y el final" (2013: 32).
} 
persona viviente, no separada de la vida ni implantada en ella, sino coincidente con ella ${ }^{15}$.

Ahora bien, esta inmanencia de vida no se alza pacíficamente sino a resguardo de un alto grado de violencia: la propia que impone el medio debido a su carestía, pero también la que se va gestando en el ascenso al poder de Plop. Me interesa recalcar el paralelismo que la narración plantea entre ese ascenso y ciertos cambios que tienen lugar en su entorno. Primero se añade al Grupo una familia, lo que resulta extraño en la estructura del clan y el individualismo que lo preside: "la mención de familia dejó a toda la gente asombrada. Era un concepto nuevo para los jóvenes y muy en desuso para el resto" (56). Más tarde, el Urso decide adoptar una opa (un ser retardado que habitualmente se condenaba al sacrificio), a pesar de la carga que supone en los desplazamientos y la caza. Después se une a Tini ("en el Grupo empezaron las murmuraciones: no era normal que dos personas estuvieran siempre juntas y en exclusividad", 83), en una forma de asociación y afectos igualmente inaudita.

A la par que Plop va escalando puestos en la jerarquía del Grupo, se perfilan también los rasgos personales que lo particularizan en el clan. Se destaca por una ambición desmedida, además de por la astucia para tramar estrategias de engaño. Pero lo que termina por distinguirlo es la conciencia que adquiere de la relatividad del tabú (116), de lo absurdo de su prohibición (practicar sexo oral).

Tras su elección como comisario general se hace construir un trono desde el que ejecuta sangrientamente sus sentencias. Mientras la comunidad deriva hacia nuevas formas de sociabilidad, él se aísla cada vez más imbuido de pulsión de muerte y crueldad. Cuando finalmente se percata de que las costumbres están cambiado, nota que las relaciones sexuales ya no se ejercen a la fuerza, lo cual debilita al Grupo: "se perdía el concepto de fuerza, del poder del más fuerte" (133) y con él su propio poder: "él tenía poder de vida y muerte" (133). Después de su decisión de terminar con la Tini y su hijo, Urso y la opa, y transgredir públicamente el tabú, el Grupo decide liquidarlo.

\footnotetext{
15 "Separando la vida de sí misma, el dispositivo de la persona es también el instrumento conceptual a través del cual se puede destinar una parte [de la vida] a la muerte (...). A este mecanismo de separación y exclusión, construido en nombre de la persona, es a lo que me gustaría contraponer un pensamiento, cuando no una práctica de lo impersonal (Esposito, 2003: 198).
} 
Especialmente significativo resulta este cambio que implica la escalada de Plop. Si en páginas atrás recordaba que en el Grupo "cada uno es dueño de su muerte" (70), acaba por atribuirse ese el poder con una violencia atroz. Resulta tentador leer este ascenso como una transposición del poder soberano y su deriva biopolítica (en las depuraciones periódicas del Grupo, en la selección de los más fuertes, en el poder inmunitario que alcanza Plop, etc. ${ }^{16}$ ) si no fuera por la ambigüedad del final de la novela. Más bien lo que Plop escenifica es ese momento fundacional de una comunidad (y su reverso inevitable de inmunidad) en el que emergen vínculos sociales fuera de la lógica de la supervivencia, surge la singularidad de sus miembros y se toma la decisión colectiva de matar al líder.

Si, como nos recuerda Hannah Arendt, lo político empieza donde acaba el reino de la necesidad (2009: 36; 1997: 62), la novela termina en ese momento de apertura, de exposición de la existencia compartida que constituye el lugar de la política, un modo de ser junto a otros que se instituye en la acción y la palabra, más allá de la urgencia por cubrir carencias básicas. Pero ese momento de apertura del grupo que empieza a constituirse en comunidad se liga al acuerdo de terminar con su líder. Si, por un lado, cabe tomarlo como una rebelión del Grupo ante el abuso de poder, por otro, puede explicarse a partir de una reacción temerosa ante la transgresión del tabú y la amenaza de desintegración de la ley que lo funda. Si la muerte de Plop libera de la violencia de sus acciones, la medida de enterrarlo vivo en un pozo no resulta menos brutal.

En todo caso, lo que se manifiesta entre la atribución del poder de matar de Plop y su aniquilación es el hecho de que cualquiera puede dar muerte a cualquiera: "la communitas lleva dentro de sí un don de muerte" (Esposito, 2003: 41). En ese espacio de relación y exposición (de contagio) que se abre en el Grupo converge lo que hace más semejantes a sus miembros: ya no la muerte a la que el medio natural los empujaba sino la posibilidad de matarse entre ellos. Por lo tanto, Plop pone en

\footnotetext{
${ }^{16}$ Es la lectura sugerida por Sánchez Idiart (2016) aunque habría que recalcar hasta dónde el caudillaje de Prop politiza la selección natural, lo que antes de su dominio venía determinado por la adaptación al medio. Sobre la inmunidad de Plop, véase Mercier (2016: 136).
} 
escena una violencia originaria que vuelve o que llega para quedarse al poner de relieve la relación entre conservación y sacrificio ${ }^{17}$.

La muerte de Plop, ¿es el final o el comienzo de un ciclo? Desconocemos su alcance; quizá adquiera visos de parricidio, instaure una nueva ley y una comunidad sostenida por la deuda de esa muerte; quizá solo haya servido para reafirmar el orden establecido y todo siga igual. Pero la temporalidad cíclica de la novela sugiere un eterno retorno, donde "el ocaso de la cultura se parece asombrosamente a su nacimiento. Final y comienzo son iguales, pasado y futuro intercambiables" (Reati, 2013: 40), nuestro origen y nuestro destino también.

Quizá por ello no sabemos nada de quién narra, más allá de su rotunda austeridad y la desnudez de su lenguaje. Solo una voz impersonal, sin atributos ni contorno humano, puede dar cuenta de la inseparabilidad entre formas de vida y existencia cualificada pero de forma aún más radical, del paradigma inmunitario como paradigma sacrificial $y$, en ese sentido, de la política como antítesis de la vida.

Una voz que se erige como un resto incierto en la representación del desecho que comparte con la crónica de Alicia Dujovne Ortiz y con las fotografías de Fernando Brito. La materialidad de los cuerpos (abandonados en la basura, entremezclados con despojos o confundidos con el barro) y su obstinación orgánica (más allá del organismo humano) pulsan la inmunidad que los ha segregado y revierten la inscripción de la naturaleza biopolítica que los desalojó como formas de vida.

\section{BibLiOgRAFÍA}

Agamben, G. (2003). Homo sacer. El poder soberano y la nuda vida. Valencia: Pre-textos.

Arendt, H. (2009). La condición humana. Buenos Aires: Paidós.

Arendt, H. (1997). ¿Qué es política? Barcelona: Paidós

Bauman, Z. (2005). Vidas desperdiciadas: la modernidad y sus parias. Barcelona: Paidós.

\footnotetext{
${ }^{17}$ La aniquilación del líder redunda en la conservación de la vida del Grupo a costa de su muerte: "lo que la comunidad sacrifica - a su autoconservación - no es otra cosa que ella misma. Ella se sacrifica no solo en el sacrificio de cada uno de sus enemigos, sino también en el de cada uno de sus miembros, dado que cada uno de estos halla en el fondo de su ser la figura originaria del primer enemigo. A este origen - al miedo que provoca- responde el sacrificio" (Esposito, 2003: 75).
} 
Butler. J. (2006). Vida precaria. El poder del duelo y la violencia. Buenos Aires: Paidós.

Cores, G. (2012). "LaNoticiaWeb en la CEAMSE: vivir y sobrevivir de la basura, al mismo tiempo". LaNoticiaWeb, 12/12/2012. Disponible en: http://www.lanoticiaweb.com.ar/noticia/25189/lanoticiaweben-la-ceamse-vivir-y-sobrevivir-de. Última visita: 15/12/2017.

Dujovne Ortiz, A. (2011). ¿Quién mató a Diego Duarte? Crónicas de la basura. Madrid: Aguilar.

Esposito, R. (2003). Communitas. Origen y destino de la comunidad. Buenos Aires: Amorrortu.

Esposito, R. (2005). Immunitas. Protección y negación de la vida. Buenos Aires: Amorrortu.

Esposito, R. (2006). Bíos, Biopolítica y filosofía. Buenos Aires: Grama.

Esposito, R. (2009). Comunidad, inmunidad y biopolítica. Barcelona: Herder.

Foucault, M. (2000). Defender la sociedad. Curso en el Collage de France (1975-1976). Buenos Aires: Fondo de Cultura Económica.

Gatti, G. (2009). "La materialidad del lado oscuro (Apuntes para una sociología de la basura)". En Gatti, G. Martínez, I. y Tejerina, B. (Eds.). Tecnología, cultura experta e identidad en la sociedad del conocimiento. Leioa: Universidad del País Vasco.

Giorgi, G. (2014). Formas comunes. Animalidad, cultura, biopolítica. Buenos Aires: Eterna Cadencia.

Giorgi, G. (2016). "Paisajes de sobrevida". Catedral tomada. Revista de Crítica Literaria Latinoamericana, 4 (7), 127-141.

Lane, J. (2012). "Perdidos en el lugar. Reflexiones sobre la tragedia y la fotografía con los paisajes de Fernando Brito". Emisférica, 8 (2).

Mbembe, A. (2011). Necropolítica. Seguido de Sobre el gobierno privado indirecto. Tenerife: Melusina.

Mercier, C. (2016). “Ecología humana en la trilogía de Rafael Pinedo: Plop, Frío y Subte". Estudios de Teoría Literaria, 10, 131-143. Disponible en:

https://fh.mdp.edu.ar/revistas/index.php/etl/article/view/1579/17 89. Última consulta: 15/12/2017.

Monroy, R. C. (2015). "La imagen del desecho. Hacia un análisis de la estética del cadáver, el desaparecido y el cuerpo como basura". 
Las Torres de Lucca, Revista Internacional de Filosofía Política, 4 (7), 71-109.

Pinedo, R. (2007). Plop. Madrid: Salto de página.

Reati, F, (2013). “¿Qué hay después del fin del mundo? Plop y lo post post-apocaliptico en Argentina". Rassegna Iberistica, 98, 27-43.

Reguillo, R. (2012). "La narcomáquina y el trabajo de la violencia: Apuntes para su decodificación". Emisférica, 8 (2).

Sánchez Idiart, C. (2016). "Restos de vida. Estéticas de la supervivencia y políticas afectivas de lo común en Rafael Pinedo y Carlos Ríos". 452 ${ }^{\circ} \mathrm{F}$. Revista de Teoría de la Literatura y Literatura Comparada, 14, 6986.

Steimberg, A. (2012). "El futuro obturado: El cronotropo aislado en la ciencia ficción argentina pos-2001". Revista Iberoamericana, LXXVIII (238-239), 127-146.

Valverde, C. (2013). “Fernando Brito: “El tema importante en mi trabajo es la denuncia". Anormalmag, 01/07/2013. Disponible en: http://www.anormalmag.com/entrevistas/fernando-brito/. Última consulta: 15/12/2017. 